\title{
Midbrain dopaminergic neuron fate specification: Of mice and embryonic stem cells Emily Gale and Meng Li*
}

\author{
Address: MRC Clinical Sciences Centre, Imperial College London, London, UK \\ Email: Emily Gale - emily.gale@imperial.ac.uk; Meng Li* - meng.li2@imperial.ac.uk \\ * Corresponding author
}

Published: 30 September 2008

Molecular Brain 2008, I:8 doi:10.1 I86/1756-6606-I-8
Received: 2 June 2008

Accepted: 30 September 2008

This article is available from: http://www.molecularbrain.com/content/I/I/8

(c) 2008 Gale and Li; licensee BioMed Central Ltd.

This is an Open Access article distributed under the terms of the Creative Commons Attribution License (http://creativecommons.org/licenses/by/2.0), which permits unrestricted use, distribution, and reproduction in any medium, provided the original work is properly cited.

\begin{abstract}
The midbrain dopaminergic (mDA) neurons of the substantia nigra and the ventral tegmental area play a fundamental role in the control of voluntary movement and the regulation of emotion, and are severely affected in Parkinson's disease. Recent advances in mouse genetics and vertebrate development have provided us with insight into the genetic cascades involved in the development of $\mathrm{mDA}$ neurons, including the induction of $\mathrm{mDA}$ neuron progenitors in the ventral mesencephalon, the specification of the mDA neuronal fate and the maintenance of postmitotic $\mathrm{mDA}$ neurons. In parallel, rapid progress has been made in the generation of DA neurons from pluripotent stem cells and the development of stem cell-based therapies for Parkinson's disease. Here, we summarize the new findings via the developmental progression of mDA neurons and outline how this knowledge has been exploited to develop novel paradigms for the in vitro generation of these neurons from embryonic stem cells.
\end{abstract}

\section{Introduction}

Dopamine containing neurons are present in different positions in the vertebrate central nervous system with the largest assembly in the midbrain. Midbrain dopaminergic (mDA) neurons are separated into functionally distinct subgroups called the substantia nigra compacta (SNC (also called the A9 group) and the ventral tegmental area (VTA (also called the A10 group) based on their position within the midbrain and the target structures which they innervate [1]. Dopaminergic neurons of the SNc primarily project to the dorsolateral striatum and regulate motor function. The VTA neurons, on the other hand, project to the ventromedial striatum, cortical areas and the limbic system and are involved in emotional behaviour and mechanisms of natural motivation and reward. In humans, the preferential degeneration of SNc neurons results in Parkinson's disease whilst defects of the VTA neuron system are implicated in psychiatric disorders.

Because of their involvement in Parkinson's disease and other mental disorders, mDA neurons have been a focus of clinical interest and a subject of intensive studies for a long time. For Parkinson's disease, a potential therapy is to replace the lost mDA neurons with healthy DA neurons that have been generated in vitro through the differentiation of stem cells. To achieve this, a comprehensive understanding of the genetic cues and extrinsic signalling cascade controlling the fate choice of pluripotent embryonic stem (ES) cells into neuroepithelial stem cells and subsequently into functional midbrain specific DA neurons is required. In this regard, recent studies have identified a number of regulatory factors that influence the 
emergence of mDA neurons during vertebrate embryogenesis. These studies not only have increased our understanding of mDA neuron development in vivo, they have also guided the development of new paradigms for the in vitro generation of mDA neurons from ES cells. In return, ES cell differentiation in vitro provides a powerful research tool for the genetic dissection of $\mathrm{mDA}$ neuron development and cell biology.

Several excellent reviews have extensively analyzed the extrinsic signalling pathways and genetic programme governing mDA neuronal differentiation and functional maturation [2-7]. In this article we summarise insights from recent studies of $\mathrm{mDA}$ neuron fate specification in animal models, highlighting the pivotal role of fundamental developmental studies in devising novel strategies harnessing ES cell differentiation to produce the mDA neuronal phenotype.

\section{From epiblast to midbrain DA neurons}

In the embryo, the pluripotent cells of the epiblast give rise to the multitude of different cell types of the adult animal. A complex series of extracellular signals and cell autonomous differentiation events transform these cells through germ layer specification, regionalisation and finally cell specific determination. In the generation of neurons of the SNc, research has focused on three major transitions: regionalisation of the neural plate, midbrain cell fate determination and finally terminal differentiation into mDA neurons (Figure 1). Differentiation of epiblast cells in culture into dopaminergic neurons parallels this pathway and knowledge gained from one system contributing to research in the other.

\section{Midbrain Regionalisation}

Regionalisation begins early in neural plate development. At its inception the neural plate is axially defined: anterior-posterior and dorsal-ventral. The lateral edges of the neural plate roll up during neuralation becoming dorsal in the newly created tube. The neural plate midline becomes the ventral-most part of the developing nervous system. This positions the midline cells to receive extrinsic signals from the underlying mesoderm as well as signalling factors from within the neural plate (Figure 1 Regionalisation). During the establishment of regional identity the anterior neural tube develops a morphological constriction that co-localises with the boundary that defines and instructs cell fate restriction: the midbrain hindbrain border (MHB). The MHB, in conjunction with extrinsic signals from the mesoderm and endogenous regional patterning genes, specifies tightly localised populations of neural tissue in the flanking midbrain and hindbrain territories. The regional specification of the midbrain establishes a molecular identity that potentiates the cells of the ventral midbrain neuroepithelium to respond to subsequent dopaminergic fate determining signals.

The axial position of the MHB is established and maintained by Fgf8 expression and the co-repressive interactions of Otx2 and Gbx2 [8-11]. MHB signalling genes, Wnt 1 and Engrailed 1 and Engrailed 2 (En1/2) are required for proliferation and survival of the ventral midbrain cells and Fgf8 is an instructive signal required for mDA neuron determination $[3,12,13]$ (Figure 1 Regionalisation). In addition, Wnt1 mutant mice showed a loss of the mDA neuronal transcription factor Pitx3 expression in the $\mathrm{Th}^{+}$cell population. Although Fgf8 is not expressed in the midbrain, it clearly plays an extrinsic role in defining midbrain cell fate. Its ability to generate ectopic mDA neurons from naïve forebrain tissue has been shown and the blockage of FGF signalling results in a loss of mDA neurons $[3,13]$. Since Fgf8 can induce Wnt1 expression it is not clear if Fgf8 acts directly on mDA neuron progenitor populations or through induction of Wnt1 [14].

Along with Fgf8 and Wnt1, Shh and Otx2 are required for specification of the midbrain region [15-17]. Interference with Shh or Otx2 signalling results in malformation or absence of the midbrain. The midbrain of the Shh mutant is reduced in size, has extensive patterning defects and contains no $\mathrm{Th}^{+}$cells [18]. In the Otx1/2 double mutant, the entire head including the midbrain is absent. More informative for the study of midbrain development was the discovery that a subtle shifting of Otx2's caudal expression boundary effects mDA neuron population size; a caudal shift results in an increase in population and a rostral one a reduction [19-21]. This increase or decrease is inversely reflected in a change in the seratonergic population, the ventral neuronal population of rostral hindbrain. These results demonstrate an Otx2 regulation of midbrain size but more importantly the switch from dopaminergic to seratonergic fate illustrates the change in regional identity controlled by Otx2 expression [22]. The ventral midbrain is also uniquely affected by Shh. Shh patterns ventral neuronal fate in the brain and the spinal cord but it is only ventral cells with the regional identity of the midbrain that respond to Shh expression by acquiring a dopaminergic cell fate [23-25].

In the spinal cord, the dorsal-ventral pattern of combinatorial and mutually exclusive areas of gene expression that determine the neural subtype is well established [26,27]. The pattern is initiated by Shh expression being induced in the floor plate cells, the ventral midline, by extrinsic Shh signalling from the underlying notochord. In the midbrain, this creates a signalling centre that, in combination with Otx2, sets up a regionally specific dorsoventral pattern of gene expression. Electroporation of Shh laterally, in the midbrain, induces a dorsally shifted archate 


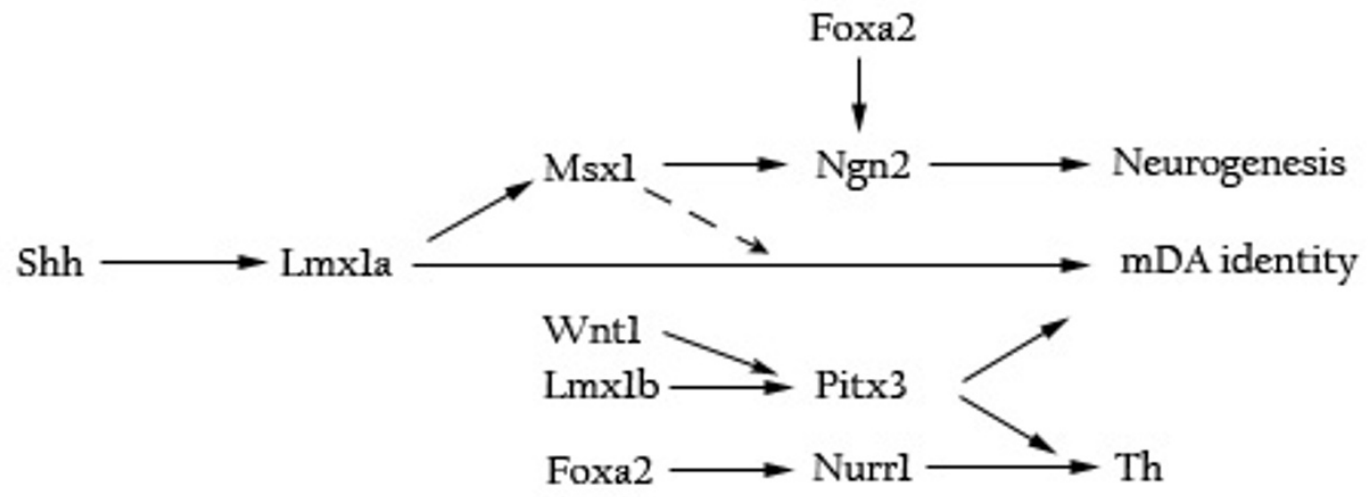

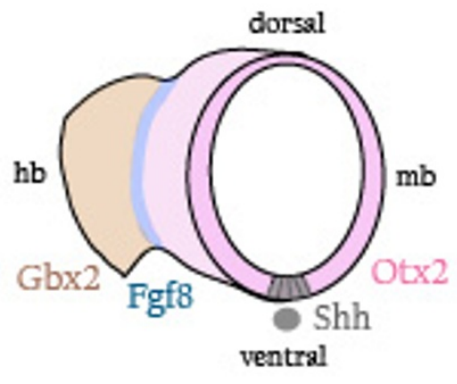

Regionalisation

E7.75-9

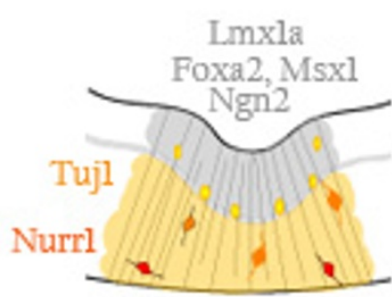

Specification

E9-14

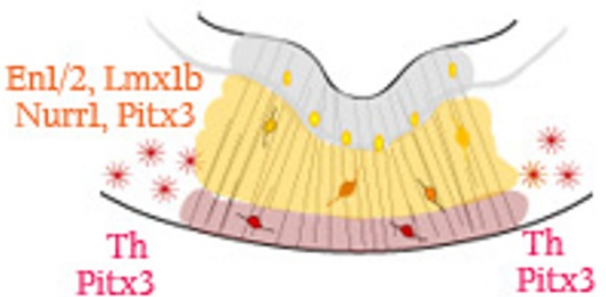

Differentiation

E11.5-15

\section{Figure I}

Schematics of the key players of mDA neuron development. Regionalisation of the neural tube (hindbrain (hb) brown, midbrain (mb) pink) establishes midbrain tissue identity via the inductive signals of Shh and Fgf8, which arise from the notochord (grey circle) and the midbrain-hindbrain border (blue) respectively, combined with Otx2 expression. This interaction enables midbrain ventral midline cells to respond to the later expression of the mDA neuron determination gene LmxIa. Specification of the mDA neuronal identity occurs within the proliferative zone (grey) of the ventral midline. Here, Msxl and Foxa2 promote generic neurogenesis via regulation of $\mathrm{Ngn} 2$ whilst $\mathrm{Lmxla}$, supported by MsxI, specifies mDA neuron cell fate. As these mDA neuron progenitors become postmitotic and enter the intermediate zone (yellow), they begin to express the pan neuronal marker Tuj I and, subsequently, the DA neuron transmitter regulator, Nurr I. LmxIb and Wnt I positively control early Pitx 3 expression in some Nurr $I^{+}$cells. The last stage in mDA neuronal differentiation proceeds as the Pitx $3^{+}$cells and the $\mathrm{Th}^{+}$cells migrate ventrally into the peripheral zone (red). The ventrolaterally located Pit $3^{+}{ }^{+}$Th- cell subpopulations coalesce leaving a Pitx3- $\mathrm{Th}^{+}$cell group in a medial position. Eventually, the early Pitx 3 expressing subpopulation migrates laterally to make up the neural population of the SNc and begin to express Th. The remaining medial, Th+, cells form the VTA. All Nurr I ${ }^{+}$ cells come to express Th and Pitx3. En I and En2 maintain survival of the mature mDA neurons in the ventral midbrain. [Colours highlight the postulated region of activity of the genes in the corresponding colour.]

pattern of expression of midbrain neuronal cell fate markers [28]. More dramatically a small point of ectopic Shh expression in the lateral midbrain generates a miniature series of bands of molecular markers duplicate to those that flank the endogenous midline [28].
Shh through binding its receptor, patched, derepresses smoothened to initiate a signalling cascade that eventually converges on the Gli family of transcription factors $[15,29]$. Dissection of the Shh signalling pathway in the midbrain points to a Gli2A-mediated control of floor plate Shh induction prior to E9 [23]. A second cascade ini- 
tiated by Shh signalling represses ventral midbrain cell death resulting from cleavage of Gli3. The complete loss of Gli2A results in a severe reduction in mDA neurons and absence of $I s l 1^{+}$cells and $N k x 2.2^{+}$cells, the more lateral ventral midbrain neuronal subtypes. The loss of Gli2A expression at $\mathrm{E} 9$ results in only a moderate decrease in the mDA neurons population but, again, a complete absence of the Isl1+ and Nkx2.2+ neurons [23]. By E11.5, neither the Gli2A-mediated Shh signalling nor the expression of Shh itself is required for normal development of the ventral midbrain neuron populations. $[23,30]$ This suggests Shh expression in the midbrain neuroepithelium specifies the mDA neuron progenitor population shortly after Shh induction but more prolonged signalling is necessary to establish more lateral neuronal identity. Expression is restricted to the floor plate and patterning is affected in lateral tissue therefore this signalling acts over many cell diameters distance [15]. Shh signalling from the floor plate seems to generate a cascade of cell differentiation events requiring no further extrinsic instructive signals that result in the pattern of the neural phenotypes of the ventral midbrain.

Recent work with conditional mutants precisely targeted to dissect the spatial regulatory activities of Otx2 has greatly broadened our understanding of the gene interactions necessary to create the midbrain dorsoventral pattern of neuronal fates $[17,31,32]$. Otx2 is normally expressed in all midbrain cells. Driving Otx2 expression by the Otx1 regulatory region results in a loss of lateral Otx2 expression and a lateral expansion of the Shh expression region [32]. Normally, Shh is expressed only in the most ventral population, which give rise to the mDA neurons, flanked by a Nkx6.1+ region, which generates the red nucleus (RN) progenitors, more lateral is the $N k x 2.2$ expressing region and the dorsal cells express Pax3. Coordinated with the induction of a broader $S h h$ domain is a dorsal shift of the $N k \times 6.1$ and $N k \times 2.2$ expressing regions and a reduction of the Pax 3 region. This change in the dorsoventral pattern leads to an increase in mDA neurons and a loss of RN neurons. A second mutant, regulating Otx2 expression using the En1 promoter, produces a loss of both ventral and lateral Otx2 expression [31]. The outcome of this manipulation was a similar lateral expansion of $S h h$, a dorsal shift in NkxG.1 expression and a dorsal reduction of the Pax expressing region but in this case the Nkx2.2 expanded ventrally into the normal Shh expressing territory. In contrast to the previous result, the combined loss of ventral and lateral Otx2 midbrain expression causes a severe reduction in mDA neurons. These experiments indicate that endogenous lateral Otx2 expression maintains Shh in its ventral domain preventing the Shh inhibition of Nkx6.1. Additionally, Otx2 represses ventral expression of Nkx2.2, which can inhibit mDA neuronal differentiation
Fgf8, Shh and Otx2, genes involved in the early regional specification, are capable of promoting dopaminergic cell specification in greater abundance in their normal location as well as ectopically in naïve hindbrain or forebrain tissue $[13,21,25,28,32]$. The genes involved with subsequent determination, such as Lmx1a, also required for dopaminergic differentiation, are limited in their inductive powers to increasing the population of mDA neurons only in the midbrain [24]. This reflects the decreasing plasticity of the developing nervous tissue as it progresses through cell fate determination.

\section{Dopaminergic fate determination}

The last few years have been rich in data contributing to understanding of the interactive molecular cascade involved in the multi-step differentiation of the mDA neuron progenitor population as well as identifying key players: Lmx1a, Ngn2, Fox2a, and Shh [23,24,29,30,33,34]. As the neuroepithelium of the midbrain develops, it thickens by cell proliferation and becomes layered. The cells in a narrow band adjacent to the ventricle retain their proliferative neural stem cell properties while other cells move out of this proliferative zone, exit the cell cycle and begin to differentiate. The mDA neuron progenitors inhabit the ventral most proliferative zone and move ventrally and then laterally as they differentiate (Figure 1 Specification). These cells express Lmx1a, Foxa2, Lmx1b, Msx1/2, Ngn2 and, at early stages, Shh. Cells at this stage acquire mDA neuronal specification and begin the final steps of postmitotic differentiation. They begin to express Nurr1 as well as the mDA neuron specific molecule, Pitx3, in the intermediate zone, which is ventral to the proliferative zone. As they reach the ventral peripheral edge of the neuroepithelium, they are fully differentiated mDA neurons and express Th (Figure 1 Differentiation) [5].

The genes expressed in the ventral proliferative zone have highly interactive regulatory mechanisms. Lmx1a, Foxa2, Ngn2, Lmx1b, Msx1/2, and Shh have all been shown to be necessary for normal mDA neuron development but of them only Shh and Lmx1a are both necessary and sufficient to induce mDA neurons [24]. The data on Shh participation in midbrain patterning has been discussed in the previous section. Two different studies have indicated that Shh is required only prior to E10.5 in mDA neuron determination and mDA neuron progenitor cells continue to be born after $S h h$ is downregulated in the ventral midbrain $[23,30]$. Lmx $1 \mathrm{a}$, on the other hand, is continually expressed during $\mathrm{mDA}$ neuron progenitor production [35]. Silencing $L m x 1 a$ in the developing midbrain with siRNA results in a dramatic reduction in $\mathrm{Nurr}^{+}$cells whilst its ectopic expression results in an expansion of the Nurr1 expressing midbrain region [24]. These data, in combination with Shh's ability to induce firstly Lmx1a and subsequently Th in naïve midbrain explants, indicates 
that Shh promotes production of mDA neurons through induction of Lmx1a [24]. Shh also is capable of regulating Foxa2 expression which in turn positively regulates Ngn2 expression (Figure 1)[30,32]. Interestingly, Foxa2 is required for normal Nurr1 expression from E10.5, the end point of Shh participation [30]. Ngn2 is also upregulated by Msx $1 / 2$ which can be induced by Lmx1a overexpression in midbrain tissue [24].

The transition of a cell from the proliferative zone to the intermediate zone is mediated by Ngn2. Loss of function mutation of Ngn2 dramatically delays and reduces the number of Nurr $1^{+}$cells in the intermediate zone and does so in a dose dependent manner [32-34]. Compound deletion of the Ngn1 and Ngn2 alleles increases the severity of this reduction [30,34]. The involvement of Ngn2 in neurogenesis is highlighted by the decrease in both total number of cells and number of neurons in the mutant intermediate zone $[30,33,34]$. The decrease of cell number is not associated with apoptosis but instead with a reduction in Hes5 and Dll1 expression, markers of proneural activity the ventricular zone [34]. Therefore, the cell loss is likely to be the result of a retardation of the rate of ventricular zone to intermediate zone transition. In the Ngn2 mutants, depleted Nurr1+ population do express Th and there is some recovery of the Nurr $1^{+}$population during development. This presents the possibility of an Ngn2-independent pathway of mDA neuron differentiation. There is evidence that in the mutant state Mash 1 can compensate for the loss of Ngn2 but since the deletion of Mash1 in normal embryos has no effect on mDA neuron development it is probable that Ngn2 is the normal mediator of neurogenesis [34]. Using Ngn2-GFP mice, Thompson et al were able to demonstrate that all mDA neurons were derived from Ngn2-GFP+ cells both in culture and in the recipient striatum following transplantation [36].

Msx1 is also expressed in the proliferative zone. While Msx1 can not induce Lmxla, it does act synergistically with Lmx1a to promote the mDA neuron progenitor population through inhibition of Nkx6.1 on the lateral edges of the ventral proliferative zone [24]. This inhibition results in Ngn2 expression in those areas. In the absence of Lmx1a, the Msx1-mediated Ngn2 expression does not result in the induction of Nurr1 [24]. This demonstrates the need for pre-specification of the $\mathrm{Ngn} 2^{+}$proliferating cells by Lmx1a to determine the mDA neuron phenotype (Figure 1 Specification).

\section{Terminal differentiation}

The final step in the differentiation of dopaminergic neurons is the expression of Th, the rate limiting enzyme in the production of dopamine. Th expression is not initiated in mDA neurons of Nurr1 null embryos [37-39]. However, the mDA neuronal lineage is properly specified as demonstrated by the expression Pitx 3 and Aldh1a1 at the appropriate stages in the ventral midbrain of Nurr1 mutant mice. Therefore, Nurr1 controls the dopaminergic neuron transmitter phenotype but does not play a role in the specification of mDA neurons. Recently it has been shown that Nurr1 regulates Th by activating the NGF-1 response element in the Th promoter region after its own phosphorylation by ERK1/2 [40,41]. Furthermore, the onset of Parkinson's disease parallels the interruption of this interaction [40].

Another transcription factor implicated in the regulation of Th and the proper differentiation of a subset of $\mathrm{mDA}$ neurons is the paired-like homeodomain protein Pitx3. Pitx3 is expressed in both the SNc and the VTA DA neurons $[42,43]$. However, lack of Pitx3 results in the preferential loss of the SNc neuronal sub-population whereas the VTA neurons are relatively intact, a phenotype that closely resemble that of Parkinson's disease [44-47]. Furthermore, analysis of the Pitx3-GFP knockin mice revealed a restricted down-regulation of Th in the SNC cells prior to their death [47]. The preferential cell loss is closely linked with the segregation of Pitx3 expression in two apparently discrete mDA neuron precursor cell populations during the onset of terminal mDA neuron differentiation. Cells located at the ventrolateral position of the marginal zone express Pitx3 prior to Th whilst cells positioned dorsomedially express Th before Pitx3 [47]. It is thought that the ventrolateral cells go on to form the SNc whilst those more medial become the VTA. The differential regulation of Pitx3 in SNc dopaminergic precursor cells dictates their strict dependence on Pitx3 for survival. The heterogeneity of the mDA neuron population and their differential dependence on Pitx3 has been further demonstrated by the identification of Aldh1a1, a retinoic acid synthesising enzyme, as a SNc specific Pitx3 target gene and the partial rescue of Pitx 3 deficient phenotype by retinoic acid [48].

Finally, the En1 and En2 homeobox transcription factors are required for the maintenance of the $\mathrm{mDA}$ neurons in late stages of foetal development and in the adulthood. In the En1/2 double mutants all mDA neurons die between E12, the onset of En1 expression, and E14 [49]. While the En1+/; En2-/- mutant has the normal mDA neuronal compliment at birth, it then begins to loose $\mathrm{Th}^{+}$neurons in the SNc while retaining those of the VTA [50]. These results indicate that $\mathrm{En} 1$ is required for $\mathrm{mDA}$ neuron maintenance and, more specifically, highlight the distinct survival requirements of SNc and VTA neurons.

\section{Steering ES cell differentiation into a DA fate}

It is generally accepted that much of ES cell differentiation in vitro mimics vertebrate development as described above. Therefore, induction of a specific cell fate should 
involve the application of known extracellular factors in a stepwise manner during the course of ES cell differentiation. The aim is to induce a cascade of transcription resembling normal development. Indeed, most differentiation paradigms reported to date apply Shh and FGF8 to differentiating ES cell cultures [51-57]. A panel of survivalpromoting factors including glial cell line-derived neurotrophic factor, neurturin, transforming growth factor- $\beta_{3}$ and dibutyryl-cAMP have been shown to promote the maturation and survival of ES cell-derived $\mathrm{Th}^{+}$neurons [58]. Furthermore, foetal midbrain astrocytes can promote the production of DA neurons from ES cells [59].

Induction with Shh and FGF8 during ES cell differentiation can result in a culture in which $\sim 30 \%$ of the neuronal population expresses Th. In these studies Shh and FGF8 are applied at the time when neural progenitor production (ie. Nestin ${ }^{+}$, Sox $1^{+}$cells) is at its peak. This is based on the understanding, supported by developmental studies, that Shh induces a DA fate via acting on ES cell derived Nestin ${ }^{+}$Sox $1^{+}$neural progenitors. However, we found that Shh and FGF8 were unable to stimulate more DA neurons in FACS (fluorescence activated cell sorting) purified Sox $1^{+}$neural progenitors than observed in un-sorted control cultures [60]. This finding indicates that DA induction occurred in 'primitive' neural progenitors prior to or at the point of Sox1 expression in differentiating ES cells.

DA neurons can also be efficiently induced by stromal cell-derived inducing activity (SDIA) produced by bone marrow derived PA6 stromal cells [61]. This protocol, which involves culturing ES cells on a layer of PA6 cells, can generate a high proportion of Th-positive neurons comparable to those derived through Shh induction as discussed above. Although the nature of SDIA remains unclear, it was suggested that SDIA might be a secreted factor that is secondarily tethered to the cell surface. A recent study implicates Wnt5 as a component of SDIA [62]. Co-culture of FACS purified Sox $1^{+}$neural progenitors with PA6 did not yield proportionally more dopaminergic neurons as compared to cultures on polylysine and laminin, suggesting that SDIA mediated DA induction also occurs at pre-Sox1 expression stage [60]. However, SDIA has a generic promoting effect on the proliferation and survival of foetal and ES cell-derived neural progenitors ([63], authors unpublished observation).

To date, the most efficient production of dopaminergic neurons from ES cells is achieved via genetic manipulation of transcription factors that are normally active in midbrain DA neurons $[24,47,64-67]$. Nurr1 is able to induce Th expression in central nervous system precursors derived from cortex, midbrain tissue, the lateral ganglionic eminence and from ES cells [46,64,67-71]. In Nurr1 expressing cultures, enhanced production of Th-positive neurons was associated with an increase in the expression level of AADC, DAT, VMAT, and Pitx3. However, engineered Nurr1 also induces Th expression in ES cell derived non-neuronal progeny [ 72$]$. This indicates that, consistent with mouse genetic studies, Nurr1 controls Th expression independent of their neuronal cell fate specification [37].

\section{Regional (midbrain) identity of ES cell-derived DA neurons}

The pathological hallmark of Parkinson's disease is the preferential loss of the substantia nigra subgroup of mDA neurons. Previous transplantation studies demonstrated that only midbrain dopaminergic cells are therapeutically useful in cell replacement therapy in animal models of Parkinson's disease [73]. Furthermore, transplanted DA neurons that form synaptic connections with the host striatum exhibit characteristics of the substantia nigra neurons demonstrated by morphology and the expression of Girk2 (a marker that is preferentially expressed by adult nigral neurons) [36]. Therefore, cells to be developed with Parkinson's disease therapy in mind must possess the capacity to generate mDA neurons, ideally those of substantia nigral character.

With increasing recognition of the necessity of generating DA neurons of 'true' midbrain property, many recent studies have investigated the induction, in ES cell derived neuronal cultures, of midbrain neural progenitor markers (e.g. Pax2, En1, Lmx1a) and the generation of midbrain specific post mitotic DA neurons (Pitx $3^{+}$, Aldh $1^{+}$) either by RT-PCR or immunocytochemistry [24,43,65,74-76]. The homeobox protein Pitx 3 is the most specific mDA neuronal marker known to date, due to its exclusive expression in mDA neurons and their postmitotic precursors $[42,43]$. The authors have previously generated Pitx3GFP knock-in ES cells as a tool for tracking mDA neuron differentiation in vitro [43]. ES cell derived Pitx3-GFP+ neurons co-express almost completely with known midbrain DA markers including Pitx3, engrailed, Lmx1a, Raldh1 (Ahd2), Nurr1 and pan-DA neuron markers such as AADC, VMAT2 and Th $[43,47,77]$. However, only $\sim 15 \%$ of SDIA induced ES cell-derived $\mathrm{Th}^{+} \mathrm{DAT}^{+}$neurons were Pitx3-GFP+, demonstrating that ES cell-derived DA neurons are heterogeneous and do not all exhibit midbrain identity [43]. Similarly, human ES cells also generate DA neurons of different regional identity [78]. More recent work with mouse ES cells showed a lack of mDA specific neuronal marker expression in $\mathrm{Th}^{+}$neurons derived using a monolayer differentiation protocol $[24,60,79]$ whilst an embryoid body based protocol gave rise to cultures with a high proportion of $\mathrm{Th}^{+}$neurons expressing Pitx3-GFP [77]. Shh was applied in both the monolayer and embryoid body differentiation paradigms so the varied efficiency in generating midbrain-specific DA neurons does not seem to be due to limited Shh sig- 
nalling. On the other hand, PA6-co-culture and embryoid body based ES cell differentiation protocols share a common feature: high local cell density at neural fate transition stage. In contrast, efficient monolayer neural differentiation entails low cell density. Together, these studies suggest that close cell-cell interaction is necessary for induction of mDA neuron phenotype.

Consistent with its role in mDA neuron ontogeny, expression of the Pitx3 transgene in mouse ES cells can promote the generation of $\mathrm{Th}^{+} \mathrm{Nurr} 1+\mathrm{DA}$ neurons co-expressing a panel of midbrain markers such as En1, Ahd2 and endogenous Pitx3. In contrast to Nurr1 overexpression, Pitx3 manipulation does not result in a significant increase in the overall number of $\mathrm{Th}^{+}$cells $[47,65]$. These findings reinforce the concept of parallel transcription machinery for DA neural transmitter phenotype and for midbrain DA neuronal identity [80]. Indeed the combined transduction of Pitx3 and Nurr1 virus lead to an increase in Th and Dat RNA expression in neural differentiated human ES cells [66]. However, a synergistic effect between these two factors on Th expression was not observed in mouse ES cells in the same study. Recently, Lmx1a and Msx1 have been shown as potent stimulators of Pitx $3^{+} \mathrm{En} 1^{+}$DA neuron generation from mouse ES cells [24]. The effect of Lmx1a requires prior Shh potentiation so exogenous supply of Shh during ES cell differentiation is needed. Msx1 can only induce $\mathrm{Th}^{+}$neuron production when it is co-transfected with an Lmx1a vector. However, transduction of Lmx1a, Msx1 and/or Pitx3 virus in cultured rat mesencephalic neural progenitors, alone or combined, did not increase the number of $\mathrm{Th}^{+}$cells [81]. Interestingly, another study observed an enhancement of $\mathrm{Th}^{+}$neuron differentiation following the co-culture of Pitx3 transfected rat neurosphere neural progenitors with foetal ventral mesencephalic tissues [82]. Together these studies suggest that the intact ventral mesencephalic tissue and differentiating ES cell cultures contain additional instructive molecules and/or exhibit intrinsic characteristics necessary for dopaminergic neuron determination.

\section{Making DA neurons from neural stem cells}

Although all available evidence demonstrates that ES cells have a greater capacity to produce dopaminergic neurons than neural stem cells (NSC) or other types of lineage-specific stem cells [52,83], for cell therapy, it may be preferable to derive DA neurons from neural stem cells (NSC). The advantages of using NSC over ES cells are two fold. Firstly, as a cell type already restricted to the neural lineage, NSC do not generate teratoma, a multilineage tumour originating from residual undifferentiated ES cells following transplantation $[69,84]$. The formation of teratomas in ES cell transplant is not only unacceptable for clinical applications, these tumour formations significantly compromise the health of the recipients and thus has hindered long term follow up behaviour analysis of grafted animals. Secondly, NSC can be derived from foetal and adult brains, thus one could envisage the potential use of a patient's own NSC in cell therapy to avoid immune rejection.

NSC can be routinely established by propagating foetal or adult neural tissues and ES cell derived neural progenitors in chemically defined culture media in the presence of FGF and EGF. However, whether propagated adherently or as cell aggregates (neurospheres), FGF and EGF expanded NSC primarily give rise to GABAergic neurons with no apparent regional identity [85-87]. This may be attributed to the deregulated dorsoventral patterning of neural progenitors by FGF during in vitro expansion [88]. The potential of NSC as a therapeutic reagent relies on our ability to maintain its full neurogenic competence. Using the human ES cell differentiation model, two recent studies identified a primitive NSC stage from which a broader spectrum of neuronal subtypes (including dopaminergic neurons) can be produced $[76,89]$. These primitive NSC are present at very early stage of ES cell neuralisation prior to FGF/EGF expansion and express similar molecular markers with that of early anterior neural epithelial cells. Morphologically, these primitive NSC assemble themselves as neural rosette and/or neural tube structures and were indeed termed as rosette neural stem cells (referred as R-NSC) by Elkabetz et al., [76]. These authors showed that Shh and Notch signalling, together with a high density culture environment, can prolong the maintenance of the rosette morphology. In contrast, FGF and EGF maintained NSC do not display rosette features and show a greater preponderance of GABAergic neuronal fate. Future work should address whether the maintenance of neural rosette morphology by Notch and Shh indeed is coupled with the maintenance of the neurogenic potency of RNSC.

Elucidation of the transcription programme associated with R-NSC status may lead to the discovery of master regulators governing NSC potency. A list of candidate marker genes has been identified by transcriptome profiling for the primitive NSC and R-NSC $[76,89]$. Regulated expression of some of these molecules may be key to preserving the full neurogenic repertoire of NSC. The identification of primitive NSC master regulators may offer the means to re-programme FGF/EGF expanded NSC back to a stage resembling early anterior neuroepithelium, in a fashion analogous to the generation of induced pluripotent stem (iPS) cells.

A similar approach may be taken to program dopaminergic competent NSC by exploiting transcription factors known to act in this specific neuronal lineage. For example, combined gene manipulation of Nurr1 (controlling 
dopaminergic neurotransmitter phenotype) with Lmx1a or components of the Wnt/Lmx1b-Pitx3 pathway (midbrain identity, Figure 1) might be able to impose a midbrain DA potential in FGF/EGF expanded NSC.

One should note that for clinical consideration, it is desirable to produce the therapeutically important somatic cell types using extrinsic growth factors or small molecules during the course of ES cell in vitro differentiation. While we are progressing toward discovering new soluble reagents, genetic based programming provides an important tool to decipher the pathways and mechanisms controlling stem cell fate choice which is fundamental for the establishment of culture parameters capable of sustaining the full complement of NSC potential. Furthermore, the timely investment in iPS related studies should prompt rapid technological developments such as protein transduction or small molecule mediated gene regulation.

\section{Summary}

The past few years have seen a rapid progress in our understanding in the genetic control of mDA neuron fate specification during foetal development. Combinatorial expression of transcription regulators provides markers for ventral mesencephalic neuroepithelial cells of different regional zones and/or at different developmental stages. These mDA neuron lineage markers have greatly facilitated the assessment of 'authentic' mDA neural phenotype that can be derived from ES cells. In addition, the availability of defined mDA neuron progenitor populations with distinct differentiation capacity isolated by lineage marker expression from existing reporter mice and ES cells has initiated the search for the most suitable cell population for cell-based transplantation therapy $[77,90]$. Most importantly, knowledge of intrinsic and extrinsic mDA neuron developmental cues has been successfully translated into novel strategies for mDA neuron production in vitro from ES cells. Combining enhanced efficiency of generating mDA neurons in vitro with the use of reporter ES cell lines that track mDA neuron precursors of different developmental stages, the ES cell based differentiation assays offer a simplified model system in which to dissect the interactions of intrinsic and extrinsic signals controlling mDA neuron specification. DA neurons generated from iPS cells, especially those harbouring Parkinson's disease mutations, provide a potential tool to study the disease process and to test the efficacy of preventative or therapeutic drugs. Even though great progress has been made, our understanding of the genetic cues controlling the induction of the mDA neuron progenitors and the specification of the mDA neuronal fate is far from complete. Further advances in the field will undoubtedly facilitate the controlled differentiation of pluripotent stem cells into clinically relevant DA neurons.

\section{Competing interests}

The authors declare that they have no competing interests

\section{Authors' contributions}

All authors participated in developing the ideas, the writing, discussion and integration of information. All authors read and approved the final manuscript.

\section{Acknowledgements}

We apologise to colleagues whose work could not be cited due to space constraints, and we refer readers to the quoted reviews for references. Work in the author's laboratory was funded by the UK Medical Research Council, the UK Parkinson's Disease Society and the European Commission FP6 programme (ESTOOLS).

\section{References}

I. Bjorklund $A$, Lindvall $O$ : Dopamine-containing systems in the CNS. Handbook of Chemical Neuroanatomy 1984, 2(Calssical Transmitters in the CNS, Part I):55- I I3.

2. Prakash N, Wurst W: Development of dopaminergic neurons in the mammalian brain. Cell Mol Life Sci 2006, 63(2): 187-206.

3. Prakash N, Brodski C, Naserke T, Puelles E, Gogoi R, Hall A, Panhuysen M, Echevarria D, Sussel L, Weisenhorn DM, Martinez S, Arenas E, Simeonn A, Wolfgang Wurst: A Wnt I-regulated genetic network controls the identity and fate of midbrain-dopaminergic progenitors in vivo. Development 2006, I33(1):89-98.

4. Ang SL: Transcriptional control of midbrain dopaminergic neuron development. Development 2006, I 33( I 8):3499-3506.

5. Smidt MP, Burbach JP: How to make a mesodiencephalic dopaminergic neuron. Nat Rev Neurosci 2007, 8(I):2I-32.

6. Wallen A, Perlmann T: Transcriptional control of dopamine neuron development. Ann N Y Acad Sci 2003, 99 I:48-60.

7. Simon HH, Bhatt L, Gherbassi D, Sgado P, Alberi L: Midbrain dopaminergic neurons: determination of their developmental fate by transcription factors. Ann N Y Acad Sci 2003, $991: 36-47$.

8. Martinez-Barbera JP, Signore M, Boyl PP, Puelles E, Acampora D, Gogoi R, Schubert F, Lumsden A, Simeone A: Regionalisation of anterior neuroectoderm and its competence in responding to forebrain and midbrain inducing activities depend on mutual antagonism between OTX2 and GBX2. Development 200I, I 28(23):4789-4800.

9. $L i J Y$, Joyner $A L:$ Otx2 and $G b \times 2$ are required for refinement and not induction of mid-hindbrain gene expression. Development 200I, I 28(24):4979-499|.

10. Nakamura $\mathrm{H}$, Watanabe $\mathrm{Y}$ : Isthmus organizer and regionalization of the mesencephalon and metencephalon. Int J Dev Biol 2005, 49(2-3):23I-235.

II. Hidalgo-Sanchez M, Simeone A, Alvarado-Mallart RM: Fgf8 and Gbx2 induction concomitant with Otx2 repression is correlated with midbrain-hindbrain fate of caudal prosencephalon. Development 1999, I 26(14):3191-3203.

12. Chi CL, Martinez S, Wurst W, Martin GR: The isthmic organizer signal FGF8 is required for cell survival in the prospective midbrain and cerebellum. Development 2003, I 30( I 2):2633-2644.

13. Ye W, Shimamura K, Rubenstein JL, Hynes MA, Rosenthal A: FGF and Shh signals control dopaminergic and serotonergic cell fate in the anterior neural plate. Cell 1998, 93(5):755-766.

14. Martinez S, Crossley PH, Cobos I, Rubenstein JL, Martin GR: FGF8 induces formation of an ectopic isthmic organizer and isthmocerebellar development via a repressive effect on Otx2 expression. Development 1999, I 26(6): I I89-1200.

15. Bayly RD, Ngo M, Aglyamova GV, Agarwala S: Regulation of ventral midbrain patterning by Hedgehog signaling. Development 2007, I34(II):21I5-2I24.

16. Prakash N, Wurst W: Genetic networks controlling the development of midbrain dopaminergic neurons. J Physiol 2006, 575(Pt 2):403-4I0. 
17. Vernay B, Koch M, Vaccarino F, Briscoe J, Simeone A, Kageyama R, Ang SL: Otx2 regulates subtype specification and neurogenesis in the midbrain. J Neurosci 2005, 25(19):4856-4867.

18. Ishibashi M, McMahon AP: A sonic hedgehog-dependent signaling relay regulates growth of diencephalic and mesencephalic primordia in the early mouse embryo. Development 2002, I 29(20):4807-48|9.

19. Suda M, Fukui M, Sogabe Y, Sato K, Morimatsu A, Arai R, Motegi F, Miyakawa T, Mabuchi I, Hirata D: Overproduction of elongation factor I alpha, an essential translational component, causes aberrant cell morphology by affecting the control of growth polarity in fission yeast. Genes Cells 1999, 4(9):517-527.

20. Acampora D, Avantaggiato V, Tuorto F, Simeone A: Genetic control of brain morphogenesis through Otx gene dosage requirement. Development 1997, I24(I8):3639-3650.

21. Broccoli $V$, Boncinelli $E$, Wurst $W$ : The caudal limit of Otx2 expression positions the isthmic organizer. Nature 1999, 40 I(6749): I64-I 68.

22. Brodski C, Weisenhorn DM, Signore M, Sillaber I, Oesterheld M, Broccoli V, Acampora D, Simeone A, Wurst W: Location and size of dopaminergic and serotonergic cell populations are controlled by the position of the midbrain-hindbrain organizer. J Neurosci 2003, 23( ( 0):4199-4207.

23. Blaess S, Corrales JD, Joyner AL: Sonic hedgehog regulates Gli activator and repressor functions with spatial and temporal precision in the mid/hindbrain region. Development 2006, 133(9): $1799-1809$.

24. Andersson E, Tryggvason U, Deng Q, Friling S, Alekseenko Z, Robert $B$, Perlmann T, Ericson J: Identification of intrinsic determinants of midbrain dopamine neurons. Cell 2006, I 24(2):393-405.

25. Ono $Y$, Nakatani T, Sakamoto $Y$, Mizuhara E, Minaki $Y$, Kumai M, Hamaguchi A, Nishimura M, Inoue Y, Hayashi H, Takahashi J, Imai T: Differences in neurogenic potential in floor plate cells along an anteroposterior location: midbrain dopaminergic neurons originate from mesencephalic floor plate cells. Development 2007, I34(I 7):32 I3-3225.

26. Jessell TM, Sanes JR: Development. The decade of the developing brain. Curr Opin Neurobiol 2000, 10(5):599-6II.

27. Jessell TM: Neuronal specification in the spinal cord: inductive signals and transcriptional codes. Nat Rev Genet 2000, I(I):20-29.

28. Agarwala S, Sanders TA, Ragsdale CW: Sonic hedgehog control of size and shape in midbrain pattern formation. Science 200I, $29|(55 I I): 2| 47-2 \mid 50$.

29. Fogel JL, Chiang C, Huang X, Agarwala S: Ventral specification and perturbed boundary formation in the mouse midbrain in the absence of Hedgehog signaling. Dev Dyn 2008, 237(5): $1359-1372$.

30. Ferri AL, Lin W, Mavromatakis YE, Wang JC, Sasaki H, Whitsett JA, Ang SL: Foxal and Foxa2 regulate multiple phases of midbrain dopaminergic neuron development in a dosagedependent manner. Development 2007, 134(I 5):276I-2769.

31. Puelles E, Annino A, Tuorto F, Usiello A, Acampora D, Czerny T, Brodski C, Ang SL, Wurst W, Simeone A: Otx2 regulates the extent, identity and fate of neuronal progenitor domains in the ventral midbrain. Development 2004, I 3 I (9):2037-2048.

32. Puelles E, Acampora D, Lacroix E, Signore M, Annino A, Tuorto $F$, Filosa S, Corte G, Wurst W, Ang SL, Simeone A: Otx dose-dependent integrated control of antero-posterior and dorso-ventral patterning of midbrain. Nat Neurosci 2003, 6(5):453-460.

33. Andersson E, Jensen JB, Parmar M, Guillemot F, Bjorklund A: Development of the mesencephalic dopaminergic neuron system is compromised in the absence of neurogenin 2 . Development 2006, I33(3):507-516.

34. Kele J, Simplicio N, Ferri AL, Mira H, Guillemot F, Arenas E, Ang SL: Neurogenin 2 is required for the development of ventral midbrain dopaminergic neurons. Development 2006, 133(3):495-505.

35. Failli V, Bachy I, Retaux S: Expression of the LIM-homeodomain gene Lmxla (dreher) during development of the mouse nervous system. Mech Dev 2002, I I 8(I-2):225-228.

36. Thompson L, Barraud P, Andersson E, Kirik D, Bjorklund A: Identification of dopaminergic neurons of nigral and ventral tegmental area subtypes in grafts of fetal ventral mesencephalon based on cell morphology, protein expres- sion, and efferent projections. J Neurosci 2005, 25(27):6467-6477.

37. Saucedo-Cardenas O, Quintana-Hau JD, Le WD, Smidt MP, Cox J], De Mayo F, Burbach JP, Conneely OM: NurrI is essential for the induction of the dopaminergic phenotype and the survival of ventral mesencephalic late dopaminergic precursor neurons. Proc Natl Acad Sci USA 1998, 95(7):40 I3-40 I8.

38. Wallen A, Zetterstrom RH, Solomin L, Arvidsson M, Olson L, Perlmann T: Fate of mesencephalic AHD2-expressing dopamine progenitor cells in NURRI mutant mice. Exp Cell Res 1999, 253(2):737-746.

39. Smits SM, Ponnio T, Conneely OM, Burbach JP, Smidt MP: Involvement of Nurrl in specifying the neurotransmitter identity of ventral midbrain dopaminergic neurons. Eur J Neurosci 2003 , 18(7): $173 \mid-1738$

40. Jacobsen KX, MacDonald H, Lemonde S, Daigle M, Grimes DA, Bulman DE, Albert PR: A Nurrl point mutant, implicated in Parkinson's disease, uncouples ERKI/2-dependent regulation of tyrosine hydroxylase transcription. Neurobiol Dis 2008, 29(1): $117-122$.

4I. Zhang T, Jia N, Fei E, Wang P, Liao Z, Ding L, Yan M, Nukina N, Zhou J, Wang G: Nurrl is phosphorylated by ERK2 in vitro and its phosphorylation upregulates tyrosine hydroxylase expression in SH-SY5Y cells. Neurosci Lett 2007, 423(2): I I8- 122.

42. Smidt MP, van Schaick HS, Lanctot C, Tremblay JJ, Cox JJ, Kleij AA van der, Wolterink G, Drouin J, Burbach JP: A homeodomain gene Ptx3 has highly restricted brain expression in mesencephalic dopaminergic neurons. Proc Natl Acad Sci USA 1997, 94(24): $13305-13310$.

43. Zhao S, Maxwell S, Jimenez-Beristain A, Vives J, Kuehner E, Zhao J, O'Brien C, de Felipe C, Semina E, Li M: Generation of embryonic stem cells and transgenic mice expressing green fluorescence protein in midbrain dopaminergic neurons. Eur J Neurosci 2004, 19(5): I |33-। I 40.

44. Smidt MP, Smits SM, Bouwmeester H, Hamers FP, Linden AJ van der, Hellemons AJ, Graw J, Burbach JP: Early developmental failure of substantia nigra dopamine neurons in mice lacking the homeodomain gene Pitx3. Development 2004, I3 I(5): I |45-I I55.

45. Munckhof $\mathrm{P}$ van den, Luk KC, Ste-Marie L, Montgomery J, Blanchet PJ, Sadikot AF, Drouin J: Pitx3 is required for motor activity and for survival of a subset of midbrain dopaminergic neurons. Development 2003, I30(I I):2535-2542.

46. Hwang DY, Ardayfio P, Kang UJ, Semina EV, Kim KS: Selective loss of dopaminergic neurons in the substantia nigra of Pitx3deficient aphakia mice. Brain Res Mol Brain Res 2003, I 14(2): |23-|3|.

47. Maxwell SL, Ho HY, Kuehner E, Zhao S, Li M: Pitx3 regulates tyrosine hydroxylase expression in the substantia nigra and identifies a subgroup of mesencephalic dopaminergic progenitor neurons during mouse development. Dev Biol 2005, 282(2):467-479.

48. Jacobs FM, Smits SM, Noorlander CW, von Oerthel L, Linden AJ van der, Burbach JP, Smidt MP: Retinoic acid counteracts developmental defects in the substantia nigra caused by Pitx 3 deficiency. Development 2007, 134(14):2673-2684.

49. Alberi L, Sgado P, Simon HH: Engrailed genes are cell-autonomously required to prevent apoptosis in mesencephalic dopaminergic neurons. Development 2004, I 3 I ( I 3):3229-3236.

50. Sgado P, Alberi L, Gherbassi D, Galasso SL, Ramakers GM, Alavian $\mathrm{KN}$, Smidt MP, Dyck RH, Simon HH: Slow progressive degeneration of nigral dopaminergic neurons in postnatal Engrailed mutant mice. Proc Natl Acad Sci USA 2006, I 03(4 I): I5242-I 5247.

5I. Zhang SC, Wernig M, Duncan ID, Brustle O, Thomson JA: In vitro differentiation of transplantable neural precursors from human embryonic stem cells. Nat Biotechnol 2001, 19(I2): I I29-1 I33.

52. Lee SH, Lumelsky N, Studer L, Auerbach JM, McKay RD: Efficient generation of midbrain and hindbrain neurons from mouse embryonic stem cells. Nat Biotechnol 2000, I8(6):675-679.

53. Li XJ, Du ZW, Zarnowska ED, Pankratz M, Hansen LO, Pearce RA, Zhang SC: Specification of motoneurons from human embryonic stem cells. Nat Biotechnol 2005, 23(2):215-22I.

54. Wichterle H, Lieberam I, Porter JA, Jessell TM: Directed differentiation of embryonic stem cells into motor neurons. Cell 2002, II 10(3):385-397. 
55. Park CH, Minn YK, Lee JY, Choi DH, Chang MY, Shim JW, Ko JY, Koh HC, Kang MJ, Kang JS, Rhie DJ, Lee YS, Son H, Moon SY, Kim KS, Lee $\mathrm{SH}$ : In vitro and in vivo analyses of human embryonic stem cell-derived dopamine neurons. I Neurochem 2005, 92(5): $1265-1276$.

56. Takagi Y, Takahashi J, Saiki H, Morizane A, Hayashi T, Kishi Y, Fukuda $\mathrm{H}$, Okamoto Y, Koyanagi M, Ideguchi M, Hayashi H, Imazato T, Kawasaki H, Suemori H, Omachi S, lida H, Itoh N, Nakatsuji N, Sasai Y, Hashimoto N: Dopaminergic neurons generated from monkey embryonic stem cells function in a Parkinson primate model. J Clin Invest 2005, I I 5(I): 102-109.

57. Yan Y, Yang D, Zarnowska ED, Du Z, Werbel B, Valliere C, Pearce RA, Thomson JA, Zhang SC: Directed differentiation of dopaminergic neuronal subtypes from human embryonic stem cells. Stem Cells 2005, 23(6):78I-790.

58. Rolletschek A, Chang H, Guan K, Czyz J, Meyer M, Wobus AM: Differentiation of embryonic stem cell-derived dopaminergic neurons is enhanced by survival-promoting factors. Mech Dev 200I, 105(I-2):93-104.

59. Roy NS, Cleren C, Singh SK, Yang L, Beal MF, Goldman SA: Functional engraftment of human ES cell-derived dopaminergic neurons enriched by coculture with telomerase-immortalized midbrain astrocytes. Nat Med 2006, I 2(I I): I259-I 268.

60. Parmar M, Li M: Early specification of dopaminergic phenotype during ES cell differentiation. BMC Dev Biol 2007, 7(I):86.

61. Kawasaki H, Mizuseki K, Nishikawa S, Kaneko S, Kuwana Y, Nakanishi S, Nishikawa SI, Sasai Y: Induction of midbrain dopaminergic neurons from ES cells by stromal cell-derived inducing activity. Neuron 2000, 28(I):31-40.

62. Hayashi H, Morizane A, Koyanagi M, Ono Y, Sasai Y, Hashimoto N, Takahashi J: Meningeal cells induce dopaminergic neurons from embryonic stem cells. Eur J Neurosci 2008, 27(2):26I-268.

63. Roybon L, Brundin P, Li JY: Stromal cell-derived inducing activity does not promote dopaminergic differentiation, but enhances differentiation and proliferation of neural stem cell-derived astrocytes. Exp Neurol 2005, 196(2):373-380.

64. Kim JH, Auerbach JM, Rodriguez-Gomez JA, Velasco I, Gavin D, Lumelsky N, Lee SH, Nguyen J, Sanchez-Pernaute R, Bankiewicz K, McKay RL: Dopamine neurons derived from embryonic stem cells function in an animal model of Parkinson's disease. Nature 2002, 4I 8(6893):50-56.

65. Chung S, Hedlund E, Hwang M, Kim DW, Shin BS, Hwang DY, Jung Kang U, Isacson O, Kim KS: The homeodomain transcription factor Pitx3 facilitates differentiation of mouse embryonic stem cells into AHD2-expressing dopaminergic neurons. Mol Cell Neurosci 2005, 28(2):24I-252.

66. Martinat C, Bacci JJ, Leete T, Kim J, Vanti WB, Newman AH, Cha JH, Gether $\mathrm{U}$, Wang $\mathrm{H}$, Abeliovich $\mathrm{A}$ : Cooperative transcription activation by Nurrl and Pitx 3 induces embryonic stem cell maturation to the midbrain dopamine neuron phenotype. Proc Natl Acad Sci USA 2006, 103(8):2874-2879.

67. Chung S, Sonntag KC, Andersson T, Bjorklund LM, Park JJ, Kim DW, Kang UJ, Isacson O, Kim KS: Genetic engineering of mouse embryonic stem cells by Nurr I enhances differentiation and maturation into dopaminergic neurons. Eur J Neurosci 2002, 16(10):1829-1838.

68. Kim JY, Koh HC, Lee JY, Chang MY, Kim YC, Chung HY, Son H, Lee YS, Studer L, McKay R, Lee SH: Dopaminergic neuronal differentiation from rat embryonic neural precursors by Nurr I overexpression. J Neurochem 2003, 85(6): I443-1454.

69. Bjorklund LM, Sanchez-Pernaute R, Chung S, Andersson T, Chen IY, McNaught KS, Brownell AL, Jenkins BG, Wahlestedt C, Kim KS, Isacson $O$ : Embryonic stem cells develop into functional dopaminergic neurons after transplantation in a Parkinson rat model. Proc Natl Acad Sci USA 2002, 99(4):2344-2349.

70. Moon YS, Smas CM, Lee K, Villena JA, Kim KH, Yun EJ, Sul HS: Mice lacking paternally expressed Pref-I/DIkI display growth retardation and accelerated adiposity. Mol Cell Biol 2002, 22(15):5585-5592.

7I. Kim KS, Kim CH, Hwang DY, Seo H, Chung S, Hong SJ, Lim JK, Anderson $\mathrm{T}$, Isacson $\mathrm{O}$ : Orphan nuclear receptor NurrI directly transactivates the promoter activity of the tyrosine hydroxylase gene in a cell-specific manner. J Neurochem 2003, 85(3):622-634.

72. Sonntag KC, Simantov R, Kim KS, Isacson O: Temporally induced Nurr I can induce a non-neuronal dopaminergic cell type in embryonic stem cell differentiation. Eur I Neurosci 2004, 19(5): I| $|4|-|| 52$

73. Hudson JL, Bickford P, Johansson M, Hoffer BJ, Stromberg I: Target and neurotransmitter specificity of fetal central nervous system transplants: importance for functional reinnervation. J Neurosci 1994, 14(1):283-290.

74. Barberi T, Klivenyi P, Calingasan NY, Lee H, Kawamata H, Loonam K, Perrier AL, Bruses J, Rubio ME, Topf N, Tabar V, Harrison NL, Beal MF, Moore MA, Studer L: Neural subtype specification of fertilization and nuclear transfer embryonic stem cells and application in parkinsonian mice. Nat Biotechnol 2003, 2I(I0): I200-I 207.

75. Perrier AL, Tabar V, Barberi T, Rubio ME, Bruses J, Topf N, Harrison $\mathrm{NL}$, Studer L: Derivation of midbrain dopamine neurons from human embryonic stem cells. Proc Natl Acad Sci USA 2004, 101: I2543-12548.

76. Elkabetz Y, Panagiotakos G, Al Shamy G, Socci ND, Tabar V, Studer $L:$ Human ES cell-derived neural rosettes reveal a functionally distinct early neural stem cell stage. Genes Dev 2008, 22(2): $152-165$.

77. Hedlund EM, Pruszak J, Lardaro T, Ludwig W, Vinuela A, Kim KS, Isacson O: Embryonic Stem (ES) Cell-derived Pitx3-eGFP Midbrain Dopamine Neurons Survive Enrichment by FACS and Function in an Animal Model of Parkinson's Disease. Stem Cells 2008.

78. Zeng X, Cai J, Chen J, Luo Y, You ZB, Fotter E, Wang Y, Harvey B, Miura T, Backman C, Chen GJ, Rao MS, Freed WJ: Dopaminergic differentiation of human embryonic stem cells. Stem Cells 2004, 22(6):925-940.

79. Ying QL, Smith AG: Defined conditions for neural commitment and differentiation. Methods Enzymol 2003, 365:327-34I.

80. Smidt MP, Asbreuk CH, Cox JJ, Chen H, Johnson RL, Burbach JP: A second independent pathway for development of mesencephalic dopaminergic neurons requires Lmx I b. Nat Neurosci 2000, 3(4):337-34I.

8I. Roybon L, Hjalt T, Christophersen NS, Li JY, Brundin P: Effects on differentiation of embryonic ventral midbrain progenitors by Lmxla, MSX1, Ngn2, and Pitx3. J Neurosci 2008, 28( I 4):3644-3656.

82. Caldwell MA, Svendsen CN: Heparin, but not other proteoglycans potentiates the mitogenic effects of FGF-2 on mesencephalic precursor cells. Exp Neurol I998, I 52(I): I-10.

83. Chung S, Shin BS, Hwang M, Lardaro T, Kang UJ, Isacson O, Kim KS: Neural precursors derived from embryonic stem cells, but not those from fetal ventral mesencephalon, maintain the potential to differentiate into dopaminergic neurons after expansion in vitro. Stem Cells 2006, 24(6): 1583-1593.

84. Brustle O, Spiro AC, Karram K, Choudhary K, Okabe S, McKay RD In vitro-generated neural precursors participate in mammalian brain development. Proc Natl Acad Sci USA 1997, 94(26): | 4809-| $48 \mid 4$.

85. Conti L, Pollard SM, Gorba T, Reitano E, Toselli M, Biella G, Sun Y, Sanzone S, Ying QL, Cattaneo E, Smith A: Niche-independent symmetrical self-renewal of a mammalian tissue stem cell. PLoS Biol 2005, 3(9):e283.

86. Jain M, Armstrong RJ, Tyers P, Barker RA, Rosser AE: GABAergic immunoreactivity is predominant in neurons derived from expanded human neural precursor cells in vitro. Exp Neurol 2003, I 82(I): II3-123.

87. Zhang SC: Neural subtype specification from embryonic stem cells. Brain Pathol 2006, 16(2): I32-142.

88. Gabay L, Lowell S, Rubin LL, Anderson DJ: Deregulation of dorsoventral patterning by FGF confers trilineage differentiation capacity on CNS stem cells in vitro. Neuron 2003, 40(3):485-499.

89. Pankratz MT, Li XJ, Lavaute TM, Lyons EA, Chen X, Zhang SC: Directed neural differentiation of human embryonic stem cells via an obligated primitive anterior stage. Stem Cells 2007, 25(6): $15 \mid 1-1520$.

90. Thompson LH, Andersson E, Jensen JB, Barraud P, Guillemot F, Parmar $M$, Bjorklund A: Neurogenin2 identifies a transplantable dopamine neuron precursor in the developing ventral mesencephalon. Exp Neurol 2006, 198(I): 183-198. 